\title{
LUDO MATEMÁTICO
}

\section{MATHEMATICAL LUDO}

\author{
Geovana Medeiros ${ }^{1}$; Francismar Holanda ${ }^{2}$.
}

\section{INTRODUÇÃO}

Muitos são os relatos de alunos por não conseguirem compreender o que lhes está sendo proposto como aprendizagem e, por conseguinte, há um imenso declínio no interesse dos mesmos em estudar matemática. Isso se dá, muitas vezes pelo modelo tradicionalista de ensino, ainda vigente na maioria das escolas.

\begin{abstract}
Muitas vezes, os professores de matemática e mesmo os livros didáticos indicam uma nova unidade pela etapa da representação: em primeiro lugar, vem a definição (representação formal do conceito); depois, alguns exemplos; a seguir situações práticas em que se pode aplicar aquele conceito. Esse, acreditamos, é um dos grandes motivos pelos quais os alunos mesmo os de cursos do nível médio, acham que matemática é uma disciplina em que se devem decorar algumas regras e aplicá-las em situações de sala de aula, e que nada tem a ver com a vida prática. (TOLEDO e TOLEDO, 1997, p.37).
\end{abstract}

Tornar a aprendizagem significativa pode ser considerado uns dos maiores desafios para os docentes, não só no campo da matemática, mas de qualquer área do conhecimento. Usufruir de estratégias como o jogo e o material concreto, pode facilitar a assimilação do conteúdo e a aprendizagem. Entretanto, deve-se saber ponderar o uso destes materiais pois, não basta apenas pôr nas mãos dos alunos um objeto e esperar que eles façam deduções, conceitos e aprendizado a que este está relacionado: "Nada deve ser dado a criança, no campo da matemática, sem primeiro apresentar-se a ela uma situação concreta que a leve a agir, a pensar, a experimentar, a descobrir, e daí, a mergulhar na abstração" (Azevedo, p. 27)

O professor deve oferecer aos seus alunos atividades interessantes, utilizando-se do real e manipulável, instigando a sua curiosidade e favorecendo a própria construção do saber. Mas infelizmente a realidade que vivenciamos na maioria dos casos, é a de professores tomando a frente de seus alunos, apenas indicando resultados prontos.

Saber que ensinar não é transferir conhecimento, mas criar as possibilidades para a sua própria produção ou a sua construção. Quando entro em uma sala de aula devo estar sendo um ser aberto a indagações, à curiosidades, às perguntas dos alunos, a suas inibições; um ser crítico e inquiridor, inquieto em face da tarefa que tenho - a de ensinar e não a de transferir conhecimento.(FREIRE, 1996, P.21).

\footnotetext{
1 Licenciatura em Matemática. IFPI-Central.geomedeiros1996@gmail.com

${ }^{2}$ Prof. Msc. em Matemática. IFPI-Central. $\underline{\text { rholanda@ifpi.edu.br }}$
} 
Visando mudar tais aspectos ao despertar mais interesse dos discentes por aprender matemática, nós fizemos uma adaptação do jogo LUDO, que resultou em uma oficina como trabalho de conclusão da disciplina Projeto Integrador-3, do $3^{\circ}$ período de matemática do IFPI.

A adaptação consistiu na implementação de objetos ao jogo, dos quais se pôde aplicar conteúdos de matemática de uma forma dinâmica e extrovertida.

As adaptações foram voltadas para alunos do ensino médio, para que estes pudessem revisar, praticar ou tirar alguma dúvida, e os conteúdos escolhidos foram expressões numéricas e equações do $1^{\circ}$ e $2^{\circ}$ graus.

\section{RELATO DE EXPERIÊNCIA}

O LUDO é um jogo de tabuleiro e dados com capacidade para até 4 jogadores, e ganha quem colocar primeiro as quatros peças no centro do jogo, onde o jogador pode escolher com qual peça avançar, de acordo com sua estratégia.

Imagem 1: Modelo do Jogo Ludo que foi usado para a realização da oficina.

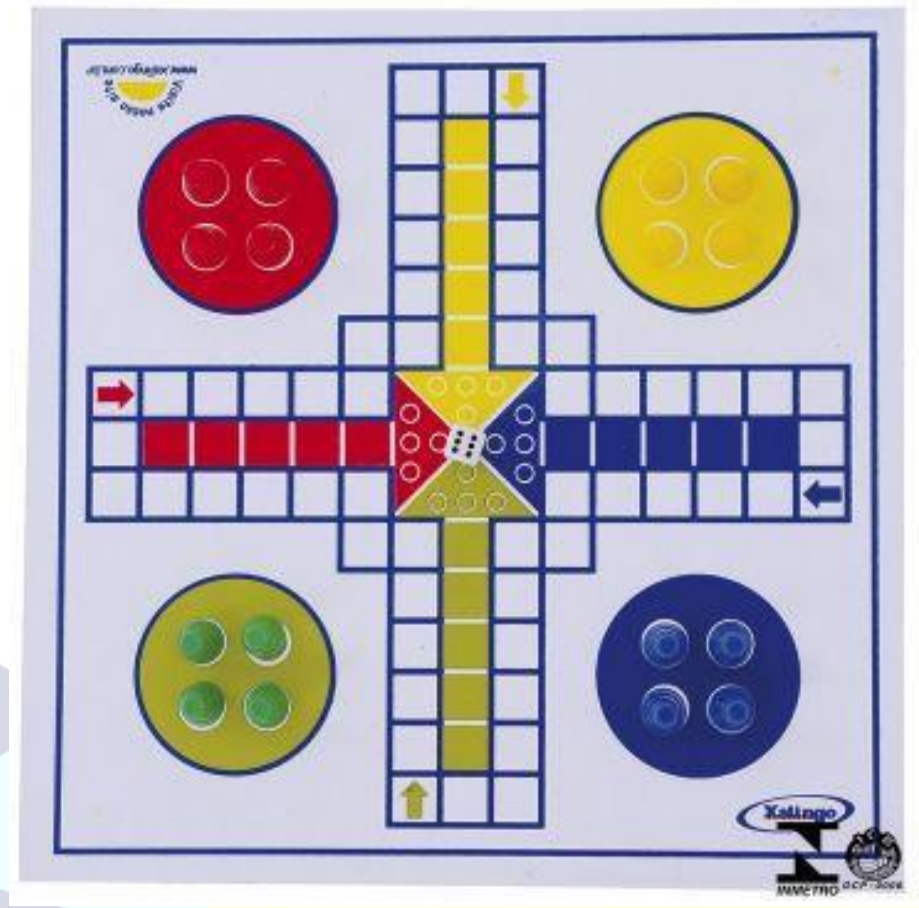

Fonte: Internet.

A adaptação a esse jogo consistiu, na colagem de quadradinhos coloridos de papel cartão, em algumas casas, de forma aleatória, onde cada cor correspondia a uma caixa de mesma cor, nas quais estão cartas com expressões numéricas, equações de $1^{\circ}$ e $2^{\circ}$ graus, todas separadas por caixa, e mais uma caixa coringa, totalizando 4 caixas. 
Sempre que uma peça de um jogador parava em uma das casas coloridas, este ia até a caixa correspondente à cor e tirava um cartão. Em seguida respondia a equação ou a expressão no tempo definido no próprio cartão. Depois de respondida, o jogador olhava a resposta no gabarito que era entregue a eles, para conferir o resultado. Caso acertasse, avançava-se a quantidade de casas que eram definidas no próprio cartão. Em caso de erro, o jogador teria que voltar uma casa.

A caixa coringa consistia em cartões variados, cujo conteúdo poderia ser bom, como avançar casas sem responder uma equação ou expressão, e colocar uma peça no fim do jogo, ou ruim, como voltar uma peça para o início do jogo.

Como o trabalho foi realizado na forma de oficina, primeiramente foi feita a divulgação em algumas salas do ensino médio do IFPI-Teresina Central. Depois com a lista de inscritos decidiram-se quantos tabuleiros seriam necessários para a realização da oficina.

Para a oficina, os materiais utilizados foram 4 folhas de papel cartão, cola, coleções, dados, caixas já com os cartões prontos, o desenho do jogo já impresso em folha A4 e quadrados coloridos para colar nas casas.

Os participantes foram divididos em grupos, onde cada um construiu seu próprio tabuleiro. Primeiro foi colado o desenho do jogo no papel cartão e em seguida eles o pintaram com cores de sua escolha. Por fim, colaram os quadradinhos no tabuleiro.

Quando todos os grupos terminaram de confeccionar seu próprio ludo matemático, demos uma rápida introdução, com resolução de exercícios, por meio de slides, de expressões numéricas e equações do $1^{\circ}$ e $2^{\circ}$ graus. Em seguida, o resto do tempo da oficina foi usado apenas para jogar.

Com a realização da oficina percebemos que houve uma melhora significativa na compreensão e resolução de questões sobre os assuntos abordados, e ainda, o maior interesse dos alunos pela matemática, que pôde ser trabalhada de forma lúdica e divertida.

Os assuntos trabalhados nessa oficina foram escolhidos com o propósito de reforçar, tirar dúvidas ou praticar exercícios de forma extrovertida, mas ele pode ser adaptado a qualquer assunto da matemática ou até a outras disciplinas, pois basta-se mudar os cartões das perguntas. 


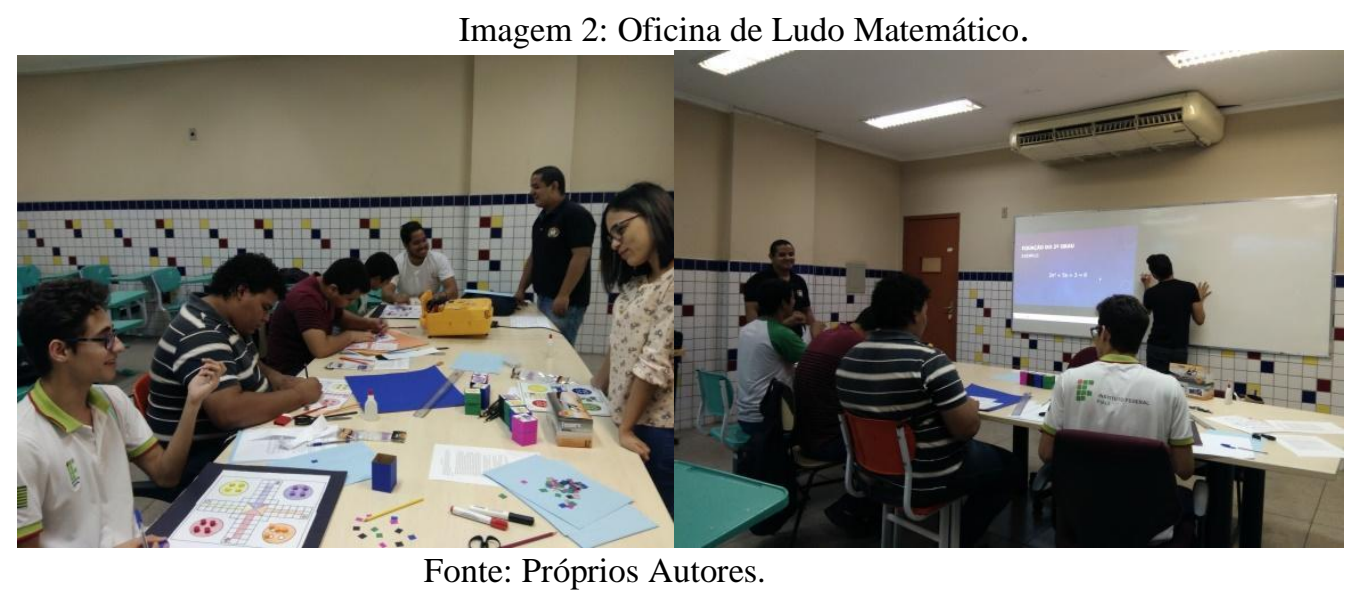

\section{CONSIDERAÇÕES}

O uso de recursos didáticos como jogos ou material concreto, pode auxiliar no aprendizado do aluno, se o for trabalhado de forma correta e de acordo com o conteúdo estudado. Assim, o professor dispõe de um "algo a mais" para implementar suas aulas, tornando-as mais dinâmicas e prazerosas, e por conseguinte, despertar um maior interesse dos seus alunos por estudar matemática.

Infelizmente a matemática ainda é vista majoritariamente como uma disciplina chata e de difícil compreensão, sobretudo pela forma tradicionalista de ensinar ainda vigente na maioria das escolas. Sendo assim, nós como futuros professores, buscamos formas de implementar nossas aulas, a fim de desmitificar que a matemática é algo chato e de difícil compreensão, e por conseguinte, despertar o interesse dos alunos em estudá-la.

\section{REFERÊNCIAS}

AZEVEDO, Edith D. M. Apresentação do trabalho Montessoriano. In: Ver. De Educação \& Matemática no. 3, 1979 (pp. 26 - 27)

FREIRE, Paulo. Pedagogia da Autonomia - Saberes Necessários à Prática Educativa. Editora Paz e Terra. Coleção Saberes. 36ª ed, 1996.

JOGO

LUDO.

Disponível

em: <https://www.google.com.br/search?q=LUDO\&source=lnms\&tbm=isch\&sa=X\&ved=0 ahUKEwjZ2oPAstfeAhUJgJAKHTRRC90Q_AUIDigB\&biw=1366\&bih=636\#imgrc=gTbzg mIQkn-D2M:> . Acesso em, 08 de Julho de 2018

TOLEDO, Marília. TOLEDO, Mauro. Didática da matemática: com a construção da matemática. São Paulo: FTD, 1997. 